\title{
INFLUENCE OF WOOD SAMPLE SIZE AND SPECIES ON THE LEACHING OF CHROMIUM AND COPPER USING DIFFERENT LAB TESTS
}

\author{
Mohsen Bahmani ${ }^{1,}$, Olaf Schmidt $^{1}$, Jörg Fromm $^{1}$, Eckhard Melcher ${ }^{2}$
}

\begin{abstract}
The present study deals with the development of standardized laboratory methods to predict depletion of biocides more accurately under service condition. Laboratory test was conducted with EN 252 standard and non-standard pine as well as spruce specimens to determine leaching of chromium and copper from stakes pressure impregnated with commercial copper- and chromium-containing preservative. Two modified laboratory test methods were carried out; first discontinuous (CEN/TS 15119-1) and second continuous water immersion (CEN/TS 15119-2). Results showed that leaching of copper in pine sapwood specimens was higher than that in spruce specimens. Moreover, copper leaching was greater in comparison to leaching chromium.
\end{abstract}

Keywords: Copper, chromium, leaching, pine, spruce.

\section{INTRODUCTION}

Good performance of wood preservative against fungi and deterioration is required for wood usage in the protection of indoor and outdoor wood structures. However, studies indicated that the preservatives can be gradually leached from treated wood into the environment during exterior applications and can be toxic to plants, animals and human health (Lebow 1996). Laboratory leaching tests such as EN 84, AWPA E11-97 and OECD have traditionally been formed utilizing a small sample size under controlled conditions. Although these studies are well repeatable conditions and are useful for shorter test durations, they have little applicability to real exposure situations (Lebow 1996). In addition it was shown that that smaller specimens have higher amounts or rate of leaching as a result of higher surface area to volume ratio (Hayes et al. 1994 Lebow 1996, Hingstion et al. 2001). Moreover, there is a uniform distribution of preservative components occurs in CEN/TS 15119 specimens whereas in EN 252 specimens, preservative distribution throughout the specimens appears to be more non-uniform as a result of an explicit gradient of wood preservative components from the surface to the center. Thus, it appears that the leaching behavior of preservatives in larger specimens and exposed under service conditions will be different compared to smaller specimens as well as laboratory tests. Therefore, in order to provide rapid comparable data for outdoor exposure larger samples have to be used in the development of laboratory methods. 
Chromium compounds are usually used as fixing agents in some preservatives. After the implementation of "European Commission concerning the placing of biocidal products on the market in 1998 (BPD 98/8/EC) " that recently replaced by Biocide Regulation EU Nr. 528/2012, the application of chrome-containing preservative formulations was accepted based on the following requirements: (1) the active substance in products containing chromic acid must be a copper compound, such as copper (II) oxide or copper hydroxide, (2) the mass ratio of chromic acid to copper (II) oxide in all products must be no more than 3:1 in all products. In addition, the following requirements have to be taken into consideration for the use of chrome-containing products: (i) treated wood should not be used in Use Class 1 or Class 2 applications as there are other chromium-free alternative products available presenting a lesser risk for these uses and should not be used in Use Class 5 (marine) applications as no data on efficacy against marine organisms are available, (ii) chromium has to be to be applied only via vacuum pressure processes, (iii) treated wood must undergo appropriate procedures to ensure fixation has been fully completed and that full reduction of hexavalent chromium to the safer chromium trivalent form has been achieved, (iv) there should be no hexavalent chromium in leachates or on the surface of treated wood when it is placed on the market. Jin et al. (1992) analyzed $19 \times 19 \times 450 \mathrm{~mm}$ Scot pine stakes treated with CCA-C after 44 months exposure in Hawaii and reported a loss of $8,9 \%$ chromium; $20,5 \%$ copper and $2 \%$ arsenic. A study on the effect of fixation, sample size, wood species and leaching protocols on the leaching of copper in laboratory tests (Habicht et al. 2003) revealed that the most important factors determining copper depletion in the different tests are sample size and fixation conditions. Wood species and leaching protocols had little influence. Lesar et al. (2008) investigated the leaching of copper and boron from treated wood with four different wood preservatives according to the three standards: SIST EN 84, SIST 1250 and OECD recommendation and found that the highest portion of leached biocides was determined according to the SIST EN 84 protocol and the lowest portion according to OECD recommendation.

The aim of the present study was fist to evaluate the leaching of chromium and copper from larger standard and nonstandard pine sapwood as well as spruce treated specimens subjected to discontinuous (CEN/TS 15119-1:2008) and continuous (CEN/TS 15119-2:2008) laboratory methods. Second, the effect of wood sample size and species on the leaching of copper and chromium should have been determined

\section{MATERIALS AND METHODS}

\section{Wood specimens, treatment and chemical analysis}

For this study, stakes of Pinus sylvestris were used in two dimensions EN $252(1990)(50 \mathrm{~cm} \times 5 \mathrm{~cm} \times 2,5$ $\mathrm{cm})$ and non-standard pine sapwood $(39 \mathrm{~cm} \times 4 \mathrm{~cm} \times 4 \mathrm{~cm})$. Spruce stakes were used as described in EN 252. Before impregnation stakes were dried at $103^{\circ} \mathrm{C}$ to measure their oven-dry mass. The stakes were treated with 1,5 percent concentration of commercial copper- and chromium-containing preservative (Rütgers Organics GmbH Company, Germany). The wood stakes were put in a pilot plant tank and subjected to vacuum of approximately "-1 bar" (manometer display) for $30 \mathrm{~min}$ followed by pressure at 8 bar for one hour. Subsequently, the impregnated stakes were wiped off and weighed with an accuracy of $0,1 \mathrm{~g}$. The concentration of chromium and copper was analyzed before and after impregnation using Inductively Coupled Plasma Optical Emission Spectrometer (ICP-OES, Perkin Elmer Optima 3000) and uptake of metals in wood was calculated according to equation:

$$
\mathrm{R}=10^{-6}\left(\mathrm{~W}_{\times} \mathrm{c}_{\mathrm{s}}\right) / \mathrm{V}
$$

$\mathrm{R}$ : uptake of metals in wood $\left(\mathrm{kg} / \mathrm{m}^{3}\right)$

$\mathrm{W}_{2}$ : weight after impregnation $(\mathrm{kg})$

$\mathrm{W}_{1}$ : initial weight $(\mathrm{kg})$ 
C: calculated by applying equation (2) which is concentration of the impregnation solution before (B) and after (A) impregnation $(\mathrm{mg} / \mathrm{kg})$.

V: stake volume $\left(\mathrm{m}^{3}\right), \mathrm{C}_{\mathrm{s}}$ is the concentration of the treating solution before (B) and after (A) treatment $(\mathrm{mg} / \mathrm{kg})$ calculated:

$$
\mathrm{C}=\left(\mathrm{C}_{\mathrm{B}}-\mathrm{C}_{\mathrm{A}}\right)+\mathrm{C}_{\mathrm{B}}
$$

Treated stakes were stored two weeks in the conditioning room $\left(20^{\circ} \mathrm{C}, 75 \%\right.$ R.H. $)$ for fixation reactions.

\section{Laboratory tests}

Before laboratory leaching tests, the stakes were cut into two $25 \mathrm{~cm}$ long specimens to give parts for discontinuous and continuous water immersion. Two modified laboratory tests were employed to perform leaching on the treated stakes. These half stakes refer to EN 252 stakes exposed in UC3 and UC4 situations. The first laboratory leaching test was conducted using CEN/TS 15119-1:2008 standard which was designed for discontinuous immersion of the samples. Each specimen was exposed in the deionized water for one min and then removed and allowed to dry. This procedure was repeated 3 times during an immersion day (nine leaching days during three weeks).

The second laboratory leaching test was done according to CEN/TS 15119-2:2008 standard which was established for continuous water immersion of the sample. Each specimen was placed into a container and deionized water per specimen was added. Both tests require an amount of $2,5 \mathrm{~cm}^{3}$ deionized water per $\mathrm{cm}^{2}$ of wood. The deionized water was replaced after 6 hour, 1 day, 2 days, 3 days, 4 days, 5 days and 6 days during 22 days of leaching. Professional services of the Institute of Inorganic and Applied Chemistry (University of Hamburg) were used for the quantification of very low metal concentrations in leachates which were obtained according to CEN/TS 15119-1/2:2008" by a graphite furnace atomic absorption spectrophotometer (GF-AAS). The analytical result was converted to the quantity emitted in the leachate in $\mathrm{mg} / \mathrm{m}^{2}$ using the volume of water and the surface area of the test specimen in square meters. The emission rate was calculated by dividing quantity emitted by interval days according to CEN/TS 15119-1/2. 2008.

\section{RESULTS AND DISCUSSION}

The initial retention of metal contents in the treated specimens is shown in Table 1. The metal retention in the pine specimens was higher in comparison to spruce specimens. The differences of the retentions could be due to the anatomical structures of the wood species (Baines and Saur 1985).

Table 1. Metal content in the treated specimens.

\begin{tabular}{|c|c|c|c|c|c|}
\hline \multicolumn{2}{|c|}{ EN 252 pine } & \multicolumn{2}{c|}{ Non-standard pine } & \multicolumn{2}{c|}{ EN 252 spruce } \\
\hline $\begin{array}{c}\mathrm{Cr} \\
(\mathrm{mg})\end{array}$ & $\begin{array}{c}\mathrm{Cu} \\
(\mathrm{mg})\end{array}$ & $\begin{array}{c}\mathrm{Cr} \\
(\mathrm{mg})\end{array}$ & $\begin{array}{c}\mathrm{Cu} \\
(\mathrm{mg})\end{array}$ & $\begin{array}{c}\mathrm{Cr} \\
(\mathrm{mg})\end{array}$ & $\begin{array}{c}\mathrm{Cu} \\
(\mathrm{mg})\end{array}$ \\
\hline 1218,75 & 706,25 & 1256,25 & 737,50 & 706,25 & 406,25 \\
\hline
\end{tabular}

Table 2 shows the amounts of chromium and copper released from the treated specimens in the discontinuous procedure according to CEN/TS 15119-1. The results show that after 3 weeks of leaching (27 minutes total submersion), the amount of leached metals was low. Since water is a dominant factor for leaching of water-soluble preservatives, a one-minute contact with water could have been too short for penetration and for the establishment of a concentration gradient of metals from the inner to the outer layers. As a result, only low amounts of metals that deposited on the wood surface were probably leached during the leaching process. Presumably metal depletion would have been higher from the discontinuous specimens if increased wetting and drying cycles had been applied. They more closely 
simulate service conditions and lead to a greater degree of check development. Moreover, cracking greatly increases the wood surface area causing an increase of preservative depletion and redistribution (Choi et al. 2004, Taylor and Cooper 2005).

The amount of chromium and copper leached from the treated specimens in the continuous approach for pine and spruce samples are given in Table 3. The leaching of chromium and copper in continuous approach was higher in comparison to the discontinuous approach. This was expected because wood continuous immersion has greater potential for metal losses than under discontinuous contact.

Table 2. Quantity of emitted chromium and copper as well as emission rate of treated wood according to CEN/TS $15119-1^{*}$.

\begin{tabular}{|c|c|c|c|c|c|c|}
\hline \multirow{2}{*}{$\begin{array}{l}\text { Time } \\
\text { (days) }\end{array}$} & \multicolumn{2}{|c|}{$\begin{array}{l}\text { Analytical results* } \\
\qquad(\mathrm{mg} / \mathrm{L})\end{array}$} & \multicolumn{2}{|c|}{$\begin{array}{l}\text { Quantity emitted* } \\
\left(\mathrm{mg} / \mathrm{m}^{2}\right)\end{array}$} & \multicolumn{2}{|c|}{$\begin{array}{c}\text { Emission rate* } \\
\left(\mathbf{m g} / \mathbf{m}^{2} \mathbf{d}\right)\end{array}$} \\
\hline & $\mathrm{Cr}$ & $\mathrm{Cu}$ & $\mathrm{Cr}$ & $\mathrm{Cu}$ & $\mathrm{Cr}$ & $\mathrm{Cu}$ \\
\hline $\begin{array}{c}\text { Half EN } 252 \text { pine } \\
1\end{array}$ & 4,45 & 22,80 & 0,11 & 0,57 & 0,11 & 0,57 \\
\hline 3 & 4,70 & 22,48 & 0,12 & 0,56 & 0,06 & 0,28 \\
\hline 5 & 3,99 & 21,70 & 0,10 & 0,54 & 0,05 & 0,27 \\
\hline 8 & 3,46 & 23,80 & 0,09 & 0,59 & 0,04 & 0,30 \\
\hline 10 & 3,38 & 23,65 & 0,08 & 0,59 & 0,04 & 0,30 \\
\hline 12 & 3,19 & 26,11 & 0,08 & 0,65 & 0,04 & 0,33 \\
\hline 15 & 2,49 & 29,11 & 0,06 & 0,73 & 0,03 & 0,37 \\
\hline 17 & 2,24 & 28,12 & 0,06 & 0,70 & 0,03 & 0,35 \\
\hline 19 & 2,19 & 28,41 & 0,05 & 0,71 & 0,03 & 0,35 \\
\hline $\begin{array}{c}\text { Half non-standard } \\
1\end{array}$ & 10,21 & 18,70 & 0,30 & 0,55 & 0,30 & 0,55 \\
\hline 3 & 9,53 & 24,30 & 0,28 & 0,72 & 0,14 & 0,36 \\
\hline 5 & 7,79 & 18,55 & 0,24 & 0,55 & 0,12 & 0,27 \\
\hline 8 & 6,54 & 23,60 & 0,19 & 0,70 & 0,10 & 0,35 \\
\hline 10 & 4,80 & 21,88 & 0,14 & 0,65 & 0,07 & 0,32 \\
\hline 12 & 5,68 & 21,54 & 0,17 & 0,64 & 0,08 & 0,32 \\
\hline 15 & 7,16 & 28,75 & 0,21 & 0,85 & 0,11 & 0,42 \\
\hline 17 & 3,52 & 31,22 & 0,10 & 0,92 & 0,05 & 0,46 \\
\hline 19 & 3,78 & 31,49 & 0,11 & & 0,06 & 0,47 \\
\hline $\begin{array}{c}\text { Half EN } 252 \text { spruce } \\
1\end{array}$ & 3,25 & 11,29 & 0,08 & 0,28 & 0,08 & 0,28 \\
\hline 3 & 4,21 & 13,27 & 0,11 & 0,33 & 0,05 & 0,17 \\
\hline 5 & 3,63 & 14,45 & 0,09 & 0,36 & 0,05 & 0,18 \\
\hline 8 & 3,40 & 14,56 & 0,08 & 0,36 & 0,04 & 0,18 \\
\hline 10 & 3,73 & 13,41 & 0,09 & 0,33 & 0,05 & 0,17 \\
\hline 12 & 2,80 & 13,72 & 0,07 & 0,34 & 0,03 & 0,17 \\
\hline 15 & 1,94 & 17,17 & 0,05 & 0,43 & 0,02 & 0,21 \\
\hline 17 & 1,59 & 18,77 & 0,04 & 0,47 & 0,02 & 0,23 \\
\hline 19 & 1,49 & 24,40 & 0,04 & 0,61 & 0,02 & 0,30 \\
\hline
\end{tabular}

*All data are mean values derived from 4 specimens treated with chromium and copper. 
Table 3. Quantity of emitted chromium and copper as well as emission rate of treated wood according to CEN/TS 15119-2*.

\begin{tabular}{|c|c|c|c|c|c|c|}
\hline \multirow[b]{2}{*}{ Time } & \multicolumn{2}{|c|}{ Analytical results* } & \multicolumn{2}{|c|}{ Quantity emitted* } & \multicolumn{2}{|c|}{ Emission rate* } \\
\hline & $\begin{array}{c}\mathrm{Cu} \\
(\mathrm{mg} / \mathrm{L})\end{array}$ & $\begin{array}{c}\mathrm{Cr} \\
(\mathrm{ug} / \mathrm{L})\end{array}$ & $\begin{array}{c}\mathrm{Cu} \\
\left(\mathrm{mg} / \mathrm{m}^{2}\right)\end{array}$ & $\begin{array}{c}\mathrm{Cr} \\
\left(\mathrm{mg} / \mathrm{m}^{2}\right)\end{array}$ & $\begin{array}{c}\mathrm{Cu} \\
\left(\mathrm{mg} / \mathrm{m}^{2} \mathrm{~d}\right)\end{array}$ & $\begin{array}{c}\mathrm{Cr} \\
\left(\mathrm{mg} / \mathrm{m}^{2} \mathrm{~d}\right)\end{array}$ \\
\hline $\begin{array}{c}\text { Half EN } 252 \text { pine } \\
6 \mathrm{~h}\end{array}$ & 0,60 & 227.93 & 15.00 & 5,70 & 60,00 & 22.79 \\
\hline $24 \mathrm{~h}$ & 1,65 & 266,38 & 41,31 & 6,66 & 41,31 & 6,66 \\
\hline $2 d$ & 3,13 & 285,35 & 78,31 & 7,13 & 39,16 & 3,57 \\
\hline $3 \mathrm{~d}$ & 4,08 & 301,20 & 102,00 & 7,53 & 34,00 & 2,51 \\
\hline $4 \mathrm{~d}$ & 5,83 & 342,76 & 145,69 & 8,57 & 36,42 & 2,14 \\
\hline $5 \mathrm{~d}$ & 5,74 & 356,80 & 143,56 & 8,92 & 28,71 & 1,78 \\
\hline $6 \mathrm{~d}$ & 6,23 & 408,33 & 155,69 & 10,21 & 25,95 & 1,70 \\
\hline $\begin{array}{c}\text { Half non-standard } \\
6 \mathrm{~h} \\
\end{array}$ & 0,66 & 207,3 & 16,38 & 5,18 & 65,50 & 20,73 \\
\hline $24 \mathrm{~h}$ & 1,62 & 227,80 & 40,44 & 5,70 & 40,44 & 5,70 \\
\hline $2 \mathrm{~d}$ & 3,08 & 260,73 & 76,88 & 6,52 & 38,44 & 3,26 \\
\hline $3 \mathrm{~d}$ & 4,29 & 371,05 & 107,25 & 9,28 & 35,75 & 3,09 \\
\hline $4 d$ & 5,52 & 394,30 & 137,99 & 9,86 & 34,50 & 2,46 \\
\hline $5 \mathrm{~d}$ & 5,87 & 499,98 & 146,63 & 12,50 & 29,33 & 2,50 \\
\hline $6 \mathrm{~d}$ & 6,77 & 553,45 & 169,31 & 13,84 & 28,2 & 2,31 \\
\hline $\begin{array}{c}\text { Half EN } 252 \text { spruce } \\
66 \mathrm{~h}\end{array}$ & 0,36 & 111,53 & 8,88 & 2,79 & 35,50 & 11,15 \\
\hline $24 \mathrm{~h}$ & 0,96 & 133,64 & 24,00 & 3,34 & 24,00 & 3,34 \\
\hline $2 d$ & 1,63 & 128,67 & 40,75 & 3,22 & 20,38 & 1,61 \\
\hline $3 d$ & 2,30 & 179,99 & 57,56 & 4,50 & 19,19 & 1,50 \\
\hline $4 \mathrm{~d}$ & 2,54 & 265,11 & 63,56 & 6,63 & 15,89 & 1,66 \\
\hline $5 d$ & 2,50 & 315,31 & 62,52 & 7,88 & 12,50 & 1,58 \\
\hline $6 \mathrm{~d}$ & 2,60 & 315,33 & 65,00 & 8,88 & 10,83 & 1,31 \\
\hline
\end{tabular}

*All data are mean values derived from 4 specimens treated with chromium and copper.

The cumulative amount of leached metals from all specimens showed that copper leaching was higher than that of chromium (Table 2 and 3). The resistance of chromium to leaching should be due to fixation properties of chromium in wood. It is known that during fixation reactions with wood, chromium reacts strongly with lignin (Eadi and Wallace 1962) while copper binds to with cellulose materials (Flomina 1967). The low amount of chromium depletion was also observed in numerous laboratory and field studies (Archer et al. 1994, Evans et al. 1994, Lebow 1996, Cooper and Ung 1997, Melcher and Wegen 2000, Garcia-Valcarcel et al. 2004, Lebow 2014, Temiz et al. 2014, Bahmani et al. 2015a, Bahmani et al. 2015b). Higher loss of copper might be explained by the fact that pine sapwood is better penetrated by the negative charged chromates than by the positive copper ions as was shown by Jüngel et al. (1998). However the main reason for the lower depletion rate of chromium should be its own fixation, meaning that a chromium ion becomes insoluble by formation of $\mathrm{Cr}-\mathrm{Cr}$ complexes or compounds like $\mathrm{Cr}(\mathrm{OH})_{3}$ (Humar et al. 2014).

The amount of metals leached after the test, expressed as a percentage of the initial amount retained in wood, is shown in Table 4. 
Table 4. Total metal amount leached from wood treated with chromium and copper after continuous water immersion.

\begin{tabular}{|c|c|c|c|c|c|c|}
\hline & \multicolumn{2}{|c|}{$\begin{array}{c}\text { Half EN 252 pine } \\
\text { stakes }\end{array}$} & \multicolumn{2}{c|}{$\begin{array}{c}\text { Half non-standard pine } \\
\text { stakes }\end{array}$} & \multicolumn{2}{c|}{$\begin{array}{c}\text { Half EN 252 spruce } \\
\text { stakes }\end{array}$} \\
\cline { 2 - 7 } & $\mathrm{Cr}$ & $\mathrm{Cu}$ & $\mathrm{Cr}$ & $\mathrm{Cu}$ & $\mathrm{Cr}$ & $\mathrm{Cu}$ \\
\hline Initial amount (mg) & 1225 & 712,50 & 1281,25 & 743,75 & 781,25 & 450 \\
\hline $\begin{array}{c}\text { Total cumulative } \\
\text { leaching amount (mg) }\end{array}$ & 2,05 & 25,74 & 1,96 & 21,68 & 1,36 & 2,68 \\
\hline Leaching (\%) & 0,17 & 3,61 & 0,15 & 2,91 & 0,17 & 1,55 \\
\hline
\end{tabular}

Table 4 also shows that the cumulative copper losses in the leachate from the half EN 252 pine were $(3,61 \%)$ in comparison to the leachate from the half non-standard pine and EN 252 spruce specimens (2,91\% and $1,55 \%$, respectively). The higher copper leaching in half EN 252 pine samples compared to non-standard could be related to their greater surface area in contact with water. The cumulative chromium losses in the leachate from all specimens were below $1 \%$.

Moreover, the determination of chromium and copper mass in the leachate and the mass balance of the two metals were checked by comparing the amount of metals detected in the leachate and the amount of remaining metals after laboratory leaching. The recovery rate of the two elements ranged from 95 to $99 \%$ for continuous and discontinuous approaches (Table 5).

Table 5. Recovery rate of chromium and copper in CC-treated wood after laboratory leaching tests.

\begin{tabular}{|c|c|c|c|c|}
\hline Metal & $\begin{array}{c}\text { Water immersion } \\
\text { type }\end{array}$ & $\begin{array}{c}\text { Initial amount } \\
\text { (mg) }\end{array}$ & $\begin{array}{c}\text { Final amount } \\
(\mathrm{mg})\end{array}$ & $\begin{array}{c}\text { Recovery rate } \\
(\%)\end{array}$ \\
\hline \multicolumn{5}{|c|}{ EN 252 pine } \\
\hline \multirow{2}{*}{ Chromium } & Discontinuous & \multirow{2}{*}{1225} & 1200 & 98 \\
\hline & Continuous & & 1187,50 & 97 \\
\hline \multirow{2}{*}{ Copper } & Discontinuous & \multirow{2}{*}{712,50} & 693,75 & 97 \\
\hline & Continuous & & 675 & 95 \\
\hline \multicolumn{5}{|c|}{ Non-standard pine } \\
\hline \multirow{2}{*}{ Chromium } & Discontinuous & \multirow{2}{*}{1281,25} & 1231,25 & 96 \\
\hline & Continuous & & 1231,25 & 96 \\
\hline \multirow{2}{*}{ Copper } & Discontinuous & \multirow{2}{*}{743,75} & 731,25 & 98 \\
\hline & Continuous & & 712,50 & 96 \\
\hline \multicolumn{5}{|c|}{ EN 252 spruce } \\
\hline \multirow{2}{*}{ Chromium } & Discontinuous & \multirow{2}{*}{718,25} & 711,06 & 99 \\
\hline & Continuous & & 703,88 & 98 \\
\hline \multirow{2}{*}{ Copper } & Discontinuous & \multirow{2}{*}{450} & 443,75 & 99 \\
\hline & Continuous & & 437,50 & 97 \\
\hline
\end{tabular}

When the mass balance was taking into consideration, for example in the half EN 252 pine samples, it was found that less than $1 \%$ and almost $4 \%$ copper leached from the samples in the discontinuous and continuous tests. Chemical mass balance metals of the wood specimens at the end of leaching 
period revealed $97 \%$ and $95 \%$ copper remaining in the wood in the discontinuous and continuous tests, respectively. These data illustrate the accuracy of results of chromium and copper determined by chemical analysis. However, it appears that there are some deviations between metal remaining in the wood and metals in the leachate (mass balance) especially for chromium. This variation could be associated with the error of this procedure since the individual analytical data of the stakes showed an error of about $\pm 5 \%$ for pine stakes and $\pm 3 \%$ for spruce stakes.

\section{CONCLUSIONS}

Results from the larger specimens could play an important role in developing more realistic standard tests for evaluating metal losses from treated wood. Chromium loss was lower than that of copper during both laboratory leaching tests. Leaching of copper in spruce stakes was lower when compared to the pine sapwood stakes. However, no significant differences in chromium leaching occurred between pine and spruce stakes. Results of the present study indicate that larger specimens (like EN 252) play an important role in developing more realistic standard tests for evaluating metal losses from treated wood.

\section{REFERENCES}

Archer, K.; Preston, A.; Chittenden, M.; Page, R. 1994. Depletion of wood preservatives after four years' marine exposure in Mt. Maunganui Harbour, NZ. The International Research Group on Wood Preservation, Stockholm. IRG/WP 94-50036.

Bahmani, M.; Fromm, J.; Schmidt, O.; Melcher, E. 2015a. Residual metal content and metal distribution in chromium/copper-treated wood after field and laboratory leaching exposure. European Journal of Wood and Wood Products 73:377-384.

Bahmani, M.; Melcher, E.; Schmidt, O.; Fromm, J. 2015b. Influence of exposure time, wood species and dimension on the remaining copper and chromium content in CC-treated wood after field and laboratory leaching tests. Holzforschung 69: 1143-1150.

Baines, E.F.; Saur, J.M. 1985. Preservative treatment of spruce and other refractory species. In: Proceedings, American Wood Preservers' Association 81:136-147.

CEN/TS 15119-1. 2008. Durability of wood and wood-based products. Determination of emissions from preservative treated wood to the environment. Part 1: wood held in the storage yard after treatment and wooden commodities in Use Class 3 (not covered, not in contact with the ground). Laboratory method.

CEN/TS 15119-2. 2008. Durability of wood and wood-based products. Determination of emissions from preservative treated wood to the environment. Part 2. wooden commodities in Use Class 4 or 5 (in contact with the ground, fresh water or sea water). Laboratory method.

Choi, S.; Ruddick, J.R.; Morris, P. 2004. Chemical redistribution in CCA treated decking. Forest Products Journal 54:33-37.

Cooper, P.A.; Ung, Y.T. 1997. Environmental impact of CCA poles in service. The International Research Group on Wood Preservation, Stockholm. IRG/WP 97-50087.

Eadi, J.; Wallace, E.M. 1962. Some observations on the fixation of copper and arsenic in Pinus sylvestris sapwood. Journal of the Institute of Wood Science 10:56-65. 
European committee for standardization. European Commission. EN. 1990. Wood preservatives. Field test methods for determining the relative protective effectiveness in ground contact, EN 252. Brussels, Belgium.

Evans, F.G.; Nossen, B.; Edlund, M.L. 1994. Leaching from field test stakes, Part 2: The distribution in and leaching from different parts of test stakes. The International Research Group on Wood Preservation, Stockholm. IRG/WP 94-50026.

Flomina, E.E. 1967. A study of the chemical mechanism of the interaction of the preservative CCA 235 with wood. Lesnoy Zhurnal 10:118-122.

Garcia-Valcarcel, AI.; Bravo, I.; Jimenez, C.; Tadeo, J.L. 2004. Influence of leaching medium and drying time between successive leaching periods on the emission of chromium, copper, and boron from treated wood. Environmental Toxicology and Chemistry Journal 23:2682-2688.

Habicht, J.; Häntzschel, D.; Wittenzellner, J. 2003. Influence of different fixation and ageing procedure on the leaching behavior of copper from selected wood preservatives in laboratory trials. The International Research Group on Wood Preservation, Stockholm. IRG/WP 03-20264.

Hayes, C.; Curran, P.M.T.; Hynes, M.J. 1994. Preservative leaching from softwoods submerged in Irish Coastal waters as measured by atomic-absorption spectrophotometry. Holzforschung 48:463473.

Hingston, J.A.; Collins, C.D.; Murphy, R.J.; Lester, J.N. 2001. Leaching of chromated copper arsenate wood preservatives: a review. Environmental Pollution 111:53-66.

Humar, M.; Thaler, N.; Melcher, E. 2014. Copper and chromium leaching from wood impregnated with chromium-copper containing preservatives: Results of different studies. IRG/WP 14-50300.

Jin, L.; Archer, K.; Preston, A.F. 1992. Depletion and biodeterioration studies with developmental wood preservative formulations. In: Proceedings, American Wood Preservers' Association 108-125.

Jüngel, P.; Melcher, E.; Peek, R.D. 1998. The non-uniform uptake of chromium and copper during the impregnation of wood using the example of a CCB-salt. The International Research Group on Wood Preservation, Stockholm. IRG/WP 98-20137.

Lebow, S. 1996. Leaching of wood preservative components and their mobility in the environment. General Technical Report FPL-GTR-93, US Department of Agriculture, Forest Products Laboratory, Madison.

Lebow, S. 2014. Effect of precipitation pattern on leaching of preservative from treated wood and implications for accelerated testing. Maderas. Ciencia y Tecnología 16(4): 423-434.

Lesar, B.; Krali, P.; Žlindra, D.; Kancilija, V.; Humar, M. 2008. Comparison of standard procedures for estimation of biocides leaching from impregnated wood. Acta Silvae et Ligni 86:59-64.

Melcher, E.; Wegen, H.W. 2000. The remaining concentration of inorganic wood preservative components in EN 252 stakes after ground contact. The International Research Group on Wood Preservation, Stockholm. IRG/WP 00-50159.

Taylor, J.L.; Cooper, P.A. 2005. Effect of climatic variables on chromated copper arsenate (CCA) leaching during aboveground exposure. Holzforschung 59:467-472.

Temiz, A.; Alfredsen G.; Yildiz, U.C.; Gezer E.D.; Köse G.; Akbas, S.; Yildiz, S. 2014. Leaching and decay resistance of alder and pine wood treated with copper based wood preservatives. Maderas. Ciencia y Tecnología 16(1):63-76. 